\title{
Comparative Studies on the Bacteria associated with Hands of School Pupils' in Government and Private Primary Schools in Dutsin-MA, Kastina State
}

\section{John Wisdom Maji ${ }^{1}$, Musa Daniel Danladi ${ }^{2}$ and Aghemwenhio Itohan Sandra ${ }^{3 *}$}

${ }^{1}$ Biological Sciences Department, Federal University, Dutsin-ma, Nigeria

${ }^{2}$ Microbiology Department, Federal University, Dutsin-ma

${ }^{3}$ Biological Sciences Department, Federal University, Dutsin-ma, Nigeria

*Corresponding author: Aghemwenhio Itohan Sandra, Biological Sciences Department, Federal University, Dutsin-ma, Nigeria, Tel: +2349027260803; E-mail: itohansandra@yahoo.com

Received date: July 12, 2018; Accepted date: December 19, 2018; Published date: December 26, 2018

Citation: Maji JW, Sandra Al, Danladi MD (2018) Comparative Studies on the Bacteria associated with Hands of School Pupils' in Government and Private Primary Schools in Dutsin-MA, Kastina State. Arch Clin Microbiol Vol No:9 Iss No:4:87

Copyright: (C) 2018 Maji JW, et al. This is an open-access article distributed under the terms of the Creative Commons Attribution License, which permits unrestricted use, distribution, and reproduction in any medium, provided the original author and source are credited.

\section{Abstract}

The importance of regular hand washing cannot be overemphasized, as this study reviewed the need to constantly wash our hands as well as the benefits derived from the practice and also pointed out the consequences of not regularly observing this healthy practice. The following species were isolated from swabs from different primary school pupils from private and government owned primary schools, Salmonella spp., Staphylococcus spp., E. coli and Bacillus spp.

Swabs from pupils showed the following result of cfu mean total viable count; $1.61 \times 104,1.52 \times 102,1.61 \times 101$ and $1.8 \times 102$. This result was obtained from pupils from the four schools; Sada primary school, Dammy preparatory School, Apollo nursery and primary school, Gummi primary school(Government school) respectively. Microbial population was more in the Government School than in the private schools.

The isolated organisms were quite resistant to most of the antibiotics used, however, Staphyloccus sp. Was most sensitive to streptomycin, while Bacillus $s p$. was most sensitive to perfloxacin, E. coli and Salmonella sp. were very sensitive to ciprofloxacin. I therefore conclude that since the hand is a major reservoir of enteric diseases, there is need to create public awareness and build a global network on hand washing bearing the health implications of dirty and contaminated hands; therefore Proper hygiene and public enlightenment of the hands in disease dissemination should be advocated.

Promotion of good hygiene by school teachers is very important, hence, key hygiene habits such as good hand washing practice that are likely to be taken further into adulthood can be adopted by encouraging millions of school children to engage in these good repetitive behaviors.
Keywords: Hand washing; Microbial population; Antibiotics

\section{Introduction}

The hand is the main body organ by which we work and maneuver through our everyday activities. Hands are the primary mode of transmission of many infectious diseases, particularly among those living and working in close proximity to one another such as class rooms, dormitories, camps and barracks.

The hand is the extremity of the superior 6 limb, hence, serves as a medium for the transfer of microorganisms from one location to the other and from one person to another. Close environments, doorknobs and other inanimate objects serving as resting vehicles of transmission all contribute to increased infection rates among these groups.

According to the US Centre for Disease Control and Prevention and the Association for Professionals in Infection Control and Epidemiology, simple hand washing is the single most important and effective method of preventing the spread of transmissible disease [1]. Human hands usually harbour microorganisms both as part of normal micro flora and microorganisms contacted from the environment.

These normal microflora such as Staphylococcus aureus resident in the human skin can therefore be passed from one individual to another. An easy way by which microbes that are not resident in the hands are contacted is by contact with surfaces such as doorknobs or handles, toilet handles and taps in restrooms. Microbes carried on the human skin are of two types i.e. resident and transient [2].

The resident types are the normal flora while the transient are contacted from the environment. Teaching appropriate hand hygienic practice have numerous benefits in various environments such as learning institution including creches, 
kidergatens, high schools and college as well as promote general wellness.

Appropriate hand hygiene practices can potentially result in minimal transmission of disease agents. Several studies have demonstrated that appropriate hand washing can reduce gastrointestinal tract diseases especially diarrhea among school children. Basic hand washing with soap and water is a brilliant way of reducing the risk and spread of infection through hand contact, but the problem of maintaining strict compliance to conventional hand washing practices is a major challenge to overcome, especially in the school premises [3].

Hand hygiene practices are difficult to perform due to factors such as lack of sinks in most classroom environments. In these situations an alternative to the conventional hand hygiene practice of hand washing with soap and water is the use of a waterless alcohol gel hand sanitizer. Waterless hand sanitizers, such as alcohol gels, offer quick, easy and effective hand hygiene.

Hammond, et al. $[4,5]$ element demonstrated that elementary school absenteeism due to illness was significantly reduced when students practiced good hand hygiene by using an alcohol gel sanitizer. Group living environments, such as residence halls, make the spread of transmissible diseases and upper respiratory illness more likely.

As in classroom situations, students in residence hall may be less likely to regularly wash their hands due to the absence of sinks in their rooms and the inconvenience of walking to the washrooms to do so. Alcohol hand sanitizers have been shown to offer an effective alternative to conventional hand washing in elementary schools [5].

Pathogens that may be present on the hand as transient types includes Salmonella spp., Shigella spp., Escherichia coli, Since human hands usually habour microorganisms both as residents and transient, it is conceivable that transfer of pathogens could occur between people who access the same area or surfaces. That chance that other persons will acquire these organisms is dependent on how long the organism can survive in the environment.

Disinfection of surfaces is also necessary to prevent infections from transient microbes especially surfaces that the hand comes in contact with mostly and frequently. Studies have shown that although these surfaces cannot be totally free from microorganisms, they can be minimized.

The high incidence of diarrheal diseases and other communicable disease among school children may be due to poor knowledge and practice of personal and environmental hygiene. Poor knowledge and practice of, and attitudes to personal hygiene, such as hand washing, has negative consequences for a child's long term overall development. Good hand washing practice is therefore a prerequisite to a child's survival $[5,6]$.

This study therefore seeks to know the types of microorganisms associated with contaminated hands of primary school pupils, to isolate and characterize bacteria present on the hands of primary school pupils, to create awareness on the possible consequences of the use of contaminated hands and to educate the pupils on the importance of sanitizing their hands after using the toilet.

\section{Materials and Methods}

\section{Study area}

This research was carried out in four selected primary schools in Dutsinma local government of Kastina State namely Sada Primary School, , Dammy Preparatory Primary School, Apollo Nursery and primary School and Gumi Primary School.

\section{Sample collection and Isolation of organisms}

With the aid of sterile swabs, 25 (twenty five) hand swabs were gotten from pupils in four different schools, each swab was introduced into 2-3 mls of peptone water in sterile sample bottles. The hand swabs were properly closed and brought to Federal university Dutsinma Microbiology Laboratory for analysis. Each hand swab rinsed fluid contained in sample bottle was aseptically inoculated into the two media namely: Mac Conkey and Chocolate agar. The peptone water in which the hand swabs was rinsed into was gently shaken and poured on the prepared media and evenly distributed on the entire surface of the media using a spreader (a sterile bent glass rod).

In the preparation of Mac Conkey agar, $15.6 \mathrm{~g}$ of the powder was dissolved in $300 \mathrm{ml}$ of distilled water. The flask was heated on hot plate for proper dissolution, corked with cotton wool and aluminum foil and was sterilized at $121^{\circ} \mathrm{C}$ by autoclaving for 15 minutes. Chocolate agar was prepared by dissolving $8.4 \mathrm{~g}$ of the nutrient agar in $300 \mathrm{ml}$ of distilled water in a conical flask. The flask was heated on hot plate for proper dissolution and corked with cotton wool and aluminum foil. It was sterilized in an autoclave at $121^{\circ} \mathrm{C}$ for 15 minutes. It was then cooled till $45^{\circ} \mathrm{C}$ and then $5 \mathrm{ml}$ blood was added, it was heated slowly and evenly to $65^{\circ} \mathrm{C}$ and cooled till $45^{\circ} \mathrm{C}$ and dispensed into petri dishes.

\section{Biochemical characterization}

Isolated microbes were characterized and identified based on colony morphology, cultural appearance and biochemical tests such as catalase test, indole test, oxidase, coagulase test based on Bergey's manual of systemic nomenclature (2007).

\section{Serial dilution}

One millimeter $(1 \mathrm{ml})$ from the stock test tube was transferred into sterile test tube containing $9 \mathrm{ml}$ of normal saline and serially diluted up $10^{-5}$ diluted factor.

\section{Isolation}

The suspected colonies of interest were sub cultured onto a fresh nutrient agar. It was done by transferring a little part of growth of the colonies from which gram staining was done, onto the plate using a sterile wire loop. A confluent streaking was done and plates were incubated at $37^{\circ} \mathrm{C}$ for 24 hours. Plates that showed pure cultures were used for biochemical test. 
Identification of microorganisms: Bergey's manual of determinative Bacteriology was used as reference for identification of Isolates. Organisms were characterized on basis of conventional biochemical tests.

Cultural characteristics: Cultural characteristics like shape, size, elevation etc. were noted on plates of chocolate agar.

\section{Gram staining procedure}

The developed bacteria colonies after 24 hours of incubation was Gram stained. A smear was prepared by emulsifying colony of bacteria from culture on solid media upon drop of water on a slide, and was air dried and heat fixed.

The smear was stained with crystal violet for 1 minute and was rinsed with water. lodine solution was added and allowed to stand for 1 minute. It was then poured off, and washed with water. The smear was then decolorized with $95 \%$ alcohol for 30 seconds.

This was rinsed under gentle running tap water and counter stained with safranin for 1 minute. The slides were rinsed with water and allowed to air dry.

The slide was mounted under microscope after drying and was observed using oil immersion objective $(\times 100)$. Gram positive bacteria retained purple color of the primary dye (crystal violet) and the Gram negative bacteria retained pink or red of the secondary.

\section{Total viable count}

At the end of 24 hours of incubation for bacteria growth, the incubated plates were removed and observed for growth. The numbers of colonies on the plates were counted. The plates were divided into four (4) quadrants, samples of quadrant were counted and multiplied by the 4 quadrant and the values were recorded. The total plate count was determined by multiplying the number of the colonies by the reciprocal of the dilution factor

The distinct colonies were further, sub cultured into nutrient agar slants and incubated at $37^{\circ} \mathrm{C}$ for 24 hours. The culture nutrient agar slants were stored at $4^{\circ} \mathrm{C}$ for later use in biochemical tests.

\section{Antibiotics sensitivity testing}

Agar preparation: Muller-Hinton agar was prepared and autoclaved, after cooling the medium, it was poured in Petri dishes and stored in refrigerator at low temperature, few plates were incubated at $35^{\circ} \mathrm{C}$ for 24 hours for sterility examination. Inoculums density was standardized by turbidity standard Barium sulphate 0.5 McFarland standard was prepared by adding $0.5 \mathrm{ml}$ aliquot of $0.048 \mathrm{~mol} / \mathrm{L} \mathrm{BaCl}_{2}(1.175 \% \mathrm{w} / \mathrm{v} \mathrm{BaCl}$. $\left.2 \mathrm{H}_{2} \mathrm{O}\right)$ to $99.5 \mathrm{ml}$ of $0.18 \mathrm{~mol} / \mathrm{ml} \mathrm{H}_{2} \mathrm{SO}_{4}(1 \% \mathrm{v} / \mathrm{v})$, the mixture was constantly stirred to maintain a suspension, turbidity standard was verified using spectrophotometer with a light path and matched cuvette to determine the absorbance. $\mathrm{BaSO}_{4}$ suspension was transferred in $4 \mathrm{ml}$ aliquots into screw caps tubes which were tightly sealed and stored at room temperature.

Preparation of inoculum: Inoculum was prepared by making a direct broth of colonies selected from 24 hours agar plates, suspension was adjusted to match $0.5 \mathrm{ml} \mathrm{McFarland} \mathrm{standard,}$ using sterile saline.

10 minutes after adjusting turbidity of the inoculums suspension, test plates were inoculated, by streaking swab dipped in the adjusted suspension over the agar surface. The sensitivity of isolates to different antibiotics was determined by using Kirby Bauer disc diffusion method, antibiotics susceptibility disc containing the following antibiotics.

Pefloxacin $(10 \mu \mathrm{g})$, Ampiclox $(10 \mu \mathrm{g})$, Zinnacef $(10 \mu \mathrm{g})$, Amoxicillin $(10 \mu \mathrm{g})$ Septrin $(30 \mu \mathrm{g})$ Rocephine $(10 \mu \mathrm{g})$ Ciprofloxacin(10 $\mu \mathrm{g})$, Gentamycin $(10 \mu \mathrm{g})$ and Streptomycin(20 $\mu \mathrm{g})$ Erythromycin $(10 \mu \mathrm{g})$. The plates were incubated for 24 hours at $37^{\circ} \mathrm{C}$. Clear zones of inhibition surrounding the antibiotics disk were, thereafter, measured with a ruler. Results were then compared with Clinical and Laboratory Standard Unit [7] to determine resistant and sensitivity strains.

\section{Results}

Table 1: Mean Total viable count for each of the four schools.

\begin{tabular}{|l|l|}
\hline Sample source (Hands of pupils) & $\begin{array}{l}\text { Total viable } \\
\text { count }\end{array}$ \\
\hline School 1 (Sada nursery and primary school) & $1.61 \times 104$ \\
\hline $\begin{array}{l}\text { School } 2 \text { (Dammy preparatory nursery and primary } \\
\text { school) }\end{array}$ & $1.52 \times 102$ \\
\hline School 3 (Apollo nursery and primary school) & $1.61 \times 101$ \\
\hline School 4 (Gummi primary school) & $1.80 \times 102$ \\
\hline
\end{tabular}

Table 1 above presents the mean bacterial count for each of the four schools sampled. School 4 had the highest mean bacterial variable count, followed by school 2 which had the lowest mean bacterial viable count while school 1 and 3 are within the same mean range of bacterial viable count.

Table 2: Microorganism isolated from the 4 schools.

\begin{tabular}{|lllllll|}
\hline $\begin{array}{l}\text { Sample source (hands of } \\
\text { pupils) }\end{array}$ & \multicolumn{4}{l|}{ Organisms isolated } & & \\
\hline $\begin{array}{l}\text { School } 1 \text { (Sada govt primary } \\
\text { school) }\end{array}$ & $\begin{array}{l}\text { Staphylococcus } \\
\text { Salmonella spp. }\end{array}$ & spp., & Escherichia & coli, \\
\hline $\begin{array}{l}\text { School } 2 \text { (Dammy preparatory } \\
\text { school) }\end{array}$ & $\begin{array}{l}\text { Staphylococcus } \\
\text { Salmonella spp. }\end{array}$ & spp., & Escherichia & coli, \\
\hline $\begin{array}{l}\text { School } \\
\text { school) }\end{array}$ & (Apollo primary & $\begin{array}{l}\text { Staphylococcus } \\
\text { Bacillus spp. }\end{array}$ & spp., & Escherichia & coli, \\
\hline $\begin{array}{l}\text { School } 4 \\
\text { school) }\end{array}$ & (Gummi primary & $\begin{array}{l}\text { Staphylococcus } \\
\text { Salmonella spp. }\end{array}$ & spp., Escherichia & coli, \\
\hline
\end{tabular}

Table 2 presents the presumed bacterial isolates from each school. Staphylococcus spp and Escherichia coli are the 
predominant bacterial isolates while Salmonella spp was moderately found and Bacillus spp. had the least.

Table 3: Susceptibility test of isolates to activities.

\begin{tabular}{|c|c|c|}
\hline $\begin{array}{l}\text { Presumed } \\
\text { organism }\end{array}$ & Sensitive & Resistance \\
\hline \multirow{7}{*}{$\begin{array}{l}\text { Staphylococcus } \\
\text { spp }\end{array}$} & Ciprofloxacin (23 mm) & Pefloxacin (13 mm) \\
\hline & Streptomycin (24 mm) & Ampliclox (9 mm) \\
\hline & Gentamicin $(21 \mathrm{~mm})$ & Zinnacef (12 mm) \\
\hline & & Amoxicillin $(10 \mathrm{~mm})$ \\
\hline & & Septin (8 mm) \\
\hline & & Rocephine (12 mm) \\
\hline & & Streptomycin (8 mm) \\
\hline \multirow{4}{*}{ Salmonella spp } & Ciprofloxacin (23 mm) & Rocephin (12 mm) \\
\hline & Septin (19 mm) & Amoxacilin (10 mm) \\
\hline & Gentamicin (18 mm) & Zinnacef (8 mm) \\
\hline & & Ampliclox (13 mm) \\
\hline \multirow{4}{*}{ Bacillus spp } & Gentamicin (21 mm) & Streptomycin $(10 \mathrm{~mm})$ \\
\hline & Zinnacef (19 mm) & Rocephin (8 mm) \\
\hline & Ciprofloxacin (22 mm) & Septin (12 mm) \\
\hline & Pefloxacin (27 mm) & Ampliclox (9 mm) \\
\hline \multirow{5}{*}{ Escherichia coli } & Ciprofloxacin (24 mm) & Ampliclox (8 mm) \\
\hline & Gentamicin (20 mm) & Streptomycin $(10 \mathrm{~mm})$ \\
\hline & & Septin (11 mm) \\
\hline & & Pefloxacin (9 mm) \\
\hline & & Erythromycin (8 mm) \\
\hline
\end{tabular}

Zone of inhibition measured in millimeter $(\mathrm{mm})$ [7]

\section{Discussion}

According to the research, it was noticed that microbial population was more in government schools than private schools. This is due to the fact that there is less hygiene amongst pupils in government schools. There are hand washing facilities like sinks and borehole which provides water in private Schools which are largely absent in Government Schools in Katsina as a result of which pupils in private schools are opportuned to wash their hands often (Table 3 ).

The presence of Staphylococcus spp. and Escherichia coli as discovered in all of the swabs could be as a result of their been resident micro flora of the human skin and therefore easily contaminate surfaces on contact. These microflora are opportunistic/potential human pathogens [8].

The presence of Escherichia coli and Staphylococcus spp. on human palms serves as quick route for contaminations. Proper hand washing will help prevent or reduce to the barest minimum spread of diseases and possible harmful effects from these organisms [3].
Bacillus species bear spores that are highly resistant hence cannot be easily destroyed and are common environmental contaminants; a study has shown that it is a micro flora of the human hand and surfaces due to its ability to form spores. Bacillus spp. has also been implicated in human pathogenesis [9]. As evident in this research, there is a high risk of infection by self-contamination among the school children which stems from the high rate of prevalence of microbes on the hands of students. The Pupils are likely to share snacks and drinks without washing their hands which could be as a result of non-chalant attitude, time constraint, carelessness, and ignorance; without knowing that their hands could harbor germs from the environment and from surface contacts, ignorance of the fact that the hand could pick up microorganisms from the environment, etc. and this ultimately puts school pupils at risk of microbial infections [10].

The Isolates were resistant to most of the antibiotics used which is in line with the findings of [10] where there was a high susceptibility of Salmonella and Streptococcus to ciprofloxacin and also in the findings of [12], where E. Coli, and Salmonella were susceptible to gentamicin. The high Susceptibility of these isolates to Ciprofloxacin and gentamicin is a welcome relief since it is a good indication of effectiveness of these antibiotics against these microorganisms hence gentamicin and ciprofloxacin are considered appropriate for treatment of E. coli, Salmonella and Streptococci infections in the study area.

The hand is the primary organ used for maneuvering our environment and picking microbes in these environments. Microorganisms are easily spread from one person to another during communication, at occasions and work places etc. and this could account for the reason why staphylococcus spp., Bacillus spp., Salmonella spp. and Escherichia coli were isolated from the hands of school pupils in all the sample Institutions, because of the ubiquitous nature of these organisms.

\section{Conclusion}

Various kinds of microorganisms are easily contacted from the environment and the hands can be the most important means of which pathogenic microorganisms are transmitted. Appropriate hygiene and public enlightenment of the hands in the spread of diseases should be advocated. Functional sinks should be placed in or around all class rooms with appropriate soaps or sanitizers, as this would encourage pupils to wash their hands often. Regular hand washing is necessary even when hands are not visibly dirty, before eating and after using the rest room. In most situations, simple hand wash shows the best result as compared with other hand treatments. Hand hygiene is equally advocated after using the rest room in cases of diarrhea and after blowing the nose in case of an upper respiratory tract infection.

School teachers should make it a point of duty to ensure pupils wash their hands regularly especially after lunch/break time as the pupils would have picked up microorganisms from each other when playing and regular hand washing should be practiced even when hands are not visibly dirty.

The use of hand sanitizer should be encouraged among the pupils after using the restroom and school campaigns should be 
organized to create awareness on the possible consequences of the use of contaminated hands.

\section{References}

1. Bloomfield SF, Aiello AE, Cookson B, O' Boyle C, Larson EL (2007) The effectiveness of hand hygiene prcedures in reducing the risks of infections in home and community settings includinh handwashing and alcohol-based hand sanitizers. American journal of infection control 35.

2. WHO Guidelines On Hand Hygiene In Health Care (2009) First Global Safety Challenge Clean Care Is Safer Care. Geneva: World Health Organization, Normal bacteria flora on hands.

3. Dodrill L, Schmidt WP, Cobb E, Donachie P, Curtis V, De-Barra M (2011) The Effect of Hand washing with water or soap on Bacterial contamination of Hands. International Science Journal on Environmental Resource Public Health 8: 97-104.

4. Hammond B, AliY, Fendler E, Dolan M, Donovan S (2000) Effect of hand sanitizer use on elementary school absenteeism. American Journal of Infection Control 28: 340-346.

5. UNICEF (2008) The state of the world's children: Child survival, Children as agents of change: Lessons from UNICEF.
6. Curtis V, Cairncross S (2003) Effect of washing hands with soap on diarrhea risk in the community: A systematic review. Lancet Infection Disinfection 3: 275-281.

7. Clinical and Laboratory Standard Institute (2008) Performance Standards for antimicrobial disc susceptibility test; approved standard-Tenth edition.

8. Nobel WC, Pitcher DG (2013) Microbial Ecology of the Human skin. Advanced Microbial Ecology 2: 245-289.

9. Collins $\mathrm{CH}$, Lyne PM (2009) Microbiological methods, 4th Edition. Biutterworths, London.

10. Aiello AE, Marshall B, Levy SB, Della-Latta P, Larson E (2009) Relationship between Triclosan and susceptibilities of bacteria isolated from hands in the community. Antimicrobial Agents of Chemotherapy 48: 2973-2979.

11. Nkang AO, Okonkwo IO, Fowotade A, Udeze AO, Ogunnusi TO, et al. (2009) Antibiotics susceptibility profiles of bacteria from clinical samples in Calabar, Nigeria. Journal of Bacteriology Research 1: 89-96.

12. Kibret $M$, Abera B (2011) Antimicrobial susceptibility patterns of $E$. coli from Clinical Sources in North East, Ethiopia. Africa Health sciences 1: 40-45. 